\title{
Multiple Jejunal Diverticulosis Complicated by Perforation: Case Report and a Brief Literature Review*
}

\author{
Luiz Carlos Benjamin do Carmo ${ }^{10}$ Fábio Guilherme Campos $^{20}$ Renato Barreto ${ }^{10}$ Diogo Fontes ${ }^{10}$ \\ Thiago Ibiapina $^{1(1)}$ Sérgio Gontscharow ${ }^{1(1)}$
}

${ }^{1}$ Emergency Surgery Division, Hospital São Luiz, Rede D’Or, São Paulo, Brazil

${ }^{2}$ Colorectal Surgery Division, Gastroenterology Department, Faculdade de Medicina, Universidade de São Paulo, São Paulo, Brazil

Address for correspondence Fábio Guilherme Campos, MD, Rua Padre João Manoel 222, Cj 120-São Paulo (SP) 01411-001, Brazil (e-mail: fgmcampos@terra.com.br).

J Coloproctol 2022;42(1):99-101.

\begin{abstract}
Background Multiple small-bowel diverticulosis comprises a rare entity with probable underestimated incidence, and that may be the reason why it is sometimes overlooked when managing cases with peritonitis.

Case report In the present paper, we report the case of a 76-year-old male presenting abdominal pain and fever in an acute setting. Computed tomography (CT) scans revealed jejunal thickening and numerous images of saccular addition that were interpreted as jejunoileal diverticulitis. After an initial period of clinical treatment, surgical management was indicated based on a worsening clinical picture and the

Keywords

- case report

- diverticulitis

- jejunoileal diverticula

- peritonitis

- laparoscopic approach presence of an extraluminal focus of gas detected in a subsequent CT scan. Through a laparoscopic approach, multiple small-bowel diverticula and a tamponade perforation were found. A segmental intestinal resection was performed, and the patient was discharged after a ten days.

Conclusions Multiple jejunal diverticulosis is a rare condition that should be remembered in the setting of an acute abdomen. As it prevails among older patients, early diagnosis with radiological aid is crucial to establish the most adequate management, including intestinal resection, if necessary.
\end{abstract}

\section{Introduction}

Jejunoileal diverticulosis (JID) was first reported in 1794 by Sommering (apud Makris ${ }^{1}$ ). In a similar manner to diverticulosis originated in the colon, its etiology is associated with

${ }^{*}$ Work developed at the Emergency Surgery Division, Hospital São Luiz, Rede D’Or, São Paulo, Brazil.

received

May 17, 2021

accepted after revision

August 6, 2021

published online

November 29, 2021 structural weakness due to vasa recta penetration in the bowel wall. Consequently, mucosa, submucosa and serosa protusions develop through the muscular layer at these weak points, forming thin-walled diverticula on the mesenteric bowel wall. ${ }^{2,3}$

In autopsy series or contrast studies, the prevalence of small-bowel diverticulosis has been estimated to vary from $\mathbf{0 . 0 2} \%$ to $\mathbf{8 . 0 \%} .{ }^{4-6}$ Besides being uncommon, these numbers

(c) 2021. Sociedade Brasileira de Coloproctologia. All rights reserved.

This is an open access article published by Thieme under the terms of the Creative Commons Attribution-NonDerivative-NonCommercial-License, permitting copying and reproduction so long as the original work is given appropriate credit. Contents may not be used for commercial purposes, or adapted, remixed, transformed or built upon. (https://creativecommons.org/ licenses/by-nc-nd/4.0/)

Thieme Revinter Publicações Ltda., Rua do Matoso 170, Rio de Janeiro, RJ, CEP 20270-135, Brazil 
Table 1 Evolutive leucocyte count (cells/mL) and C-reactive protein values $(\mu \mathrm{g} / \mathrm{mL})$

\begin{tabular}{|l|l|l|l|l|l|l|l|l|l|}
\hline Day & 1 & 2 & 3 & 4 & 5 & 6 & 7 & 9 & 11 \\
\hline Leucocyte count & 14,280 & 10,460 & 7,690 & 6,600 & 5,190 & 9,080 & 7,480 & 8,340 & 10,010 \\
\hline C-reactive protein & 13.80 & 13.09 & 14.01 & 9.37 & 6.22 & 2.83 & 2.44 & 6.46 & 1.59 \\
\hline
\end{tabular}

Note: Surgery was performed on day 7.

are probably underestimated because most cases remain undetected, and are incidentally during radiological investigations. $^{3}$

Jejunoileal diverticulosis prevails among men aged between 60 and 70 years. Isolated or multiple lesions in the duodenum, jejunum and ileum may be found, and JID may even coexist with colonic diverticula. ${ }^{7}$ The diverticula located in the jejunum and ileum occur less frequently than the duodenal ones, but they are associated with a much greater chance of developing complications. ${ }^{8}$

This entity is usually asymptomatic, but it may present non-specific symptoms such as intermittent abdominal discomfort, dyspepsia, bloating or abdominal fullness, and constipation. ${ }^{1}$

Due to its rarity, there is no consensus regarding the treatment of asymptomatic JID, although the common sense recommends no treatment in the absence of significant symptoms. However, the occurrence of severe complications may require surgical management. Jejunal perforation is the most frequent complication, but obstruction and diverticular bleeding may also occur. ${ }^{9,10}$ Overall, complications are reported in $\sim 10 \%$ of the patients. ${ }^{6}$

In the present paper, we describe a rare case of jejunoileal perforated diverticula treated by laparoscopic approach. Proper documentation and case description aim to increase awareness that this uncommon entity should not be overlooked in the differential diagnosis when treating an acute abdomen.

\section{Case Report}

We report a case of a 76-year-old male patient who presented to the hospital complaining of abdominal pain and fever. Upon physical examination, he presented tachycardia, abdominal distension associated with abdominal pain, and no signs of peritonitis. The initial laboratory tests showed leukocytosis and a high level of C-reactive protein (CRP), as it is demonstrated in - Table 1.

Large spectrum antibiotic therapy was introduced (on day 1 ), and the patient presented initial clinical amelioration and remained stable. A computed tomography (CT) scan ( - Fig. 1) on day 2 revealed mesenteric edema in the mesogastrium area, increased number of local lymph nodes, jejunal wall thickening, and some images of saccular addition (one mesuring $2.4 \mathrm{~cm}$ ). Due to the worsening of clinical picture and laboratory tests, a new radiological evaluation five days later was performed, and it revealed the presence of an extraluminal focus of gas while the patient still had symptoms of abdominal pain. Subsequently, a laparoscopic approach was indicated, during which a non-Meckel small- bowel diverticulum with signs of acute inflammation and a blocked perforation were found (-Fig. 2). Other multiple diverticula were identified along the small bowel without signs of inflammation (-Fig. $\mathbf{3}$ ).

We performed a segmental jejunum resection with primary intracorporeal latero-lateral enteroanastomosis with the aid of a linear stapler. During the postoperative period, the patient presented prolonged gastroparesia and ileus, but was discharged from the hospital on the tenth postoperative day.
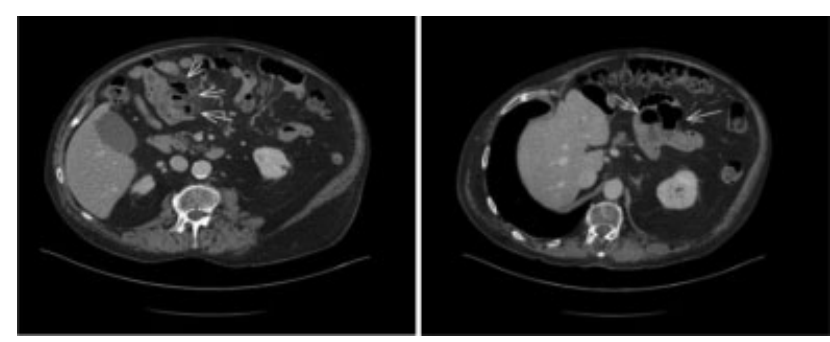

Fig. 1 (Left and right). Preoperative computed tomography scan showing thickened smal- bowel loops (left) and many diverticula (right).

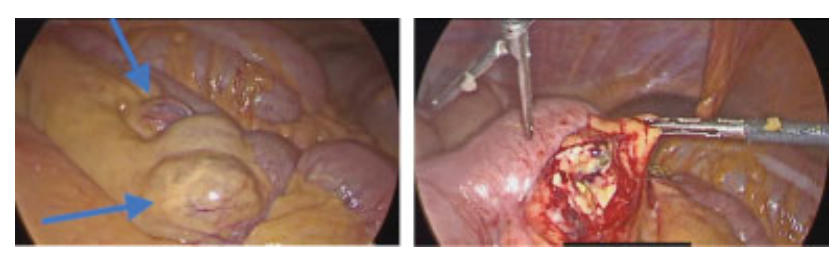

Fig. 2 (Left and right). Small-bowel diverticula (left) and intestinal perforation (right).

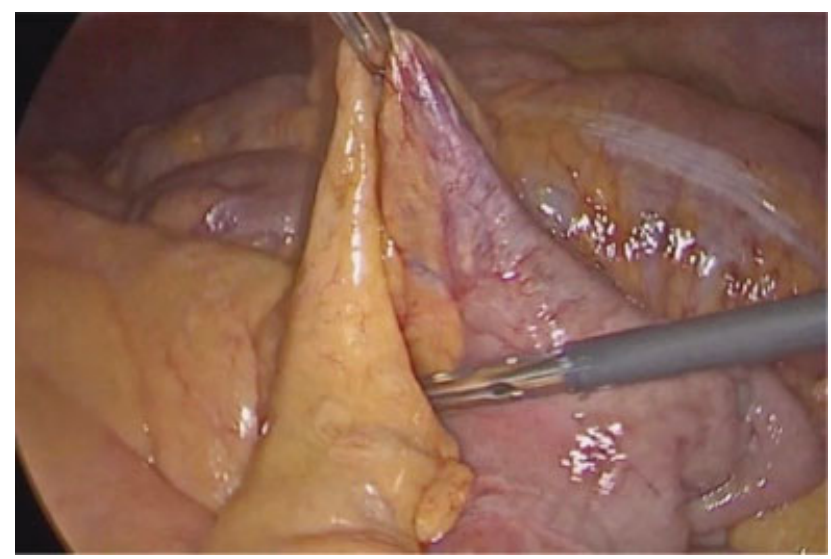

Fig. 3 Intraoperative aspect of Meckel diverticula. 
Besides being a very rare condition, JID should be considered in differential diagnosis of acute abdomen, especially in men at the sixth or seventh decades of life. Complications that may require surgery, such as peritonitis, abscess, bleeding or intestinal obstruction, should be promptly treated. A laparoscopic approach may be helpful in achieving a more accurate diagnostic evaluation and providing a minimally invasive treatment.

\section{Discussion}

Diverticulosis of the jejunum and ileum is a relatively rare small-bowel disease. These lesions are formed by false diverticula with projections of mucosa and serosa without the muscular layer, causing manifestations such as diverticulitis, bleeding, perforation, or obstruction.

As they prevail in an aged cohort, the main challenge is to establish an accurate diagnosis and provide effective treatment. Thus, physicians and surgeons should have a high index of suspicion when patients present with chronic vague symptoms such as central abdominal pain, malabsorption, nausea and anemia, which may easily lead to misdiagnosis. ${ }^{3,11}$

Moreover, it is important to note that patients may be completely asymptomatic or present severe complications requiring emergency surgery, especially local inflammation, microperforations, and mucosal necrosis, leading to adhesions, abscesses, fistulas and peritonitis. ${ }^{12}$

The radiological evaluation with CT scans using intravenous contrast is considered an important part of investigation. ${ }^{3}$ In the present case, it enabled us to diagnose the occurrence of intestinal perforation and to find multiple diverticula before surgery. ${ }^{13}$ Local signs of inflammation, the presence of extraluminal gas and liquids associated with multiple areas with dilation and wall thickening were the main findings in our patient.

However, in a recent and interesting retrospective study on 26 patients treated in 4 Italian centers, Bellio et al. ${ }^{7}$ attested that CT was effective for the diagnosis in $35 \%$ of the patients, but also helped diagnose abscess drainage in $8 \%$.

In face of the rarity of the disease, many aspects regarding its epidemiology and clinical presentation have not been studied, and treatment guidelines have not been established. Besides that, clinical suspicion requires no diagnostic delay due to the reported mortality of $40 \%$ in perforated cases. ${ }^{14}$ Thus, a tailored management is advised for patients, taking into consideration the individual's health and the surgeon's experience.

Incidental diagnoses obviously do not require any previous interventions. ${ }^{15}$ However, in the aforementioned Italian series, ${ }^{7}$ surgery was considered crucial for diagnosis and treatment in 21 out of 26 patients admitted for unspecific abdominal pain with an average age of 77 years. ${ }^{7}$ In the present case, the laparoscopic approach enabled us to establish the final diagnosis and to perform a minimally-invasive resection.

The initial surgical steps must include a thorough evaluation of the small bowel considering that most diverticula will probably be located in the proximal segments. Their occurrence is a significant finding that requires careful intestinal manipulation in the presence of complications such as adhesions, inflammation, fistulas and perforation.

Finally, the present reports on the challenges involved in the diagnosis and treatment of small-bowel diverticulosis. It is a rare condition that should not be overlooked when evaluating older patients in an acute setting. Early diagnosis is essential, and may be accomplished with the aid of CT scans to make a surgical decision. In the operating room, a careful evaluation of the bowel will help the surgical team decide on different extensions of intestinal resection and even deviation when necessary.

\section{Conflict of Interests}

The authors have no conflict of interests to declare.

\section{References}

1 Makris K, Tsiotos GG, Stafyla V, Sakorafas GH. Small intestinal nonmeckelian diverticulosis. J Clin Gastroenterol 2009;43(03): 201-207

2 Ejaz S, Vikram R, Stroehlein JR. Non-meckel small intestine diverticulitis. Case Rep Gastroenterol 2017;11(02):462-472

3 Ramistella AM, Brenna M, Fasolini F, De Monti M. Jejuno-ileal diverticulitis: A disorder not to underestimate. Int J Surg Case Rep 2019;58:81-84

4 Mohi RS, Moudgil A, Bhatia SK, Seth K, Kaur T. Complicated Jejunal Diverticulosis: Small Bowel Volvulus with Obstruction. Iran J Med Sci 2016;41(06):548-551

5 Staszewicz W, Christodoulou M, Proietti S, Demartines N. Acute ulcerative jejunal diverticulitis: case report of an uncommon entity. World J Gastroenterol 2008;14(40):6265-6267

6 Transue DL, Hanna TN, Shekhani H, Rohatgi S, Khosa F, Johnson JO. Small bowel diverticulitis: an imaging review of an uncommon entity. Emerg Radiol 2017;24(02):195-205

7 Bellio G, Kurihara H, Zago M, et al. Jejunoileal diverticula: a broad spectrum of complications. ANZ J Surg 2020;90(7-8):1454-1458

8 Miller RE, McCabe RE, Salomon PF, Knox WG. Surgical complications of small bowel diverticula exclusive of Meckel's. Ann Surg 1970;171(02):202-210

9 Gao JY, Chen JF, Su H, et al. Acute Massive Gastrointestinal Bleeding in the Elderly. J Coll Physicians Surg Pak 2018;28(06): S78-S80

10 Viscosi F, Pintabona G, Foti A, Cucinotta E, Mazzeo C. Therapeutic strategies for perforated jejunal diverticulitis. A case report. Ann Ital Chir 2019;8:S2239253-X1903072X

11 Khan HS, Ayyaz M. Jejunal diverticulosis presenting as an acute emergency. J Coll Physicians Surg Pak 2015;25(1, Suppl 1) S20-S21

12 Aispuro IO, Yazzie NP. Diverticulitis of isolated jejunal diverticulum complicated by small bowel obstruction secondary to de novo enterolith formation. J Surg Case Rep 2019;2019(05):rjz151

13 de Bree E, Grammatikakis J, Christodoulakis M, Tsiftsis D. The clinical significance of acquired jejunoileal diverticula. Am J Gastroenterol 1998;93(12):2523-2528

14 Kassir R, Boueil-Bourlier A, Baccot S, et al. Jejuno-ileal diverticulitis: Etiopathogenicity, diagnosis and management. Int J Surg Case Rep 2015;10:151-153

15 Syllaios A, Koutras A, Zotos PA, et al. Jejunal diverticulitis mimicking small bowel perforation: case report and review of the literature. Chirurgia (Bucur) 2018;113(04):576-581 